University of Nebraska - Lincoln

DigitalCommons@University of Nebraska - Lincoln

Faculty Publications, Department of Psychology

Psychology, Department of

$2-2012$

\title{
Executive function deficits in preschool children with ADHD and DBD
}

\author{
Kim Schoemaker \\ Utrecht University, The Netherlands, k.schoemaker@umcutrecht.nl \\ Tessa Bunte \\ University Medical Center, Utrecht University, The Netherlands \\ Sandra A. Wiebe \\ University of Alberta, sandra.wiebe@ualberta.ca \\ Kimberly A. Espy \\ University of Nebraska-Lincoln, kespy2@unl.edu \\ Maja Deković \\ Utrecht University, The Netherlands \\ See next page for additional authors
}

Follow this and additional works at: https://digitalcommons.unl.edu/psychfacpub

Schoemaker, Kim; Bunte, Tessa; Wiebe, Sandra A.; Espy, Kimberly A.; Deković, Maja; and Matthys, Walter, "Executive function deficits in preschool children with ADHD and DBD" (2012). Faculty Publications, Department of Psychology. 600.

https://digitalcommons.unl.edu/psychfacpub/600

This Article is brought to you for free and open access by the Psychology, Department of at DigitalCommons@University of Nebraska - Lincoln. It has been accepted for inclusion in Faculty Publications, Department of Psychology by an authorized administrator of DigitalCommons@University of Nebraska - Lincoln. 


\section{Authors}

Kim Schoemaker, Tessa Bunte, Sandra A. Wiebe, Kimberly A. Espy, Maja Deković, and Walter Matthys 


\title{
Executive function deficits in preschool children with ADHD and DBD
}

\author{
Kim Schoemaker, ${ }^{1,2}$ Tessa Bunte, ${ }^{2}$ Sandra A. Wiebe, ${ }^{3,4}$ \\ Kimberly Andrews Espy, ${ }^{4,5}$ Maja Deković, ${ }^{1}$ and Walter Matthys ${ }^{1,2}$ \\ 1. Department of Child and Adolescent Studies, Utrecht University, Utrecht \\ 2. Department of Child and Adolescent Psychiatry and Rudolf Magnus Institute of Neuroscience, \\ University Medical Center Utrecht, Utrecht, The Netherlands \\ 3. Department of Psychology, University of Alberta, Edmonton, AB, Canada \\ 4. Department of Psychology, University of Nebraska-Lincoln, Lincoln, NE \\ 5. Department of Psychology, University of Oregon, Eugene, OR, USA \\ Corresponding author - Kim Schoemaker, Department of Child and Adolescent Psychiatry, University Medical Center Utrecht, \\ P.O. Box 85500, 3508 GA Utrecht, The Netherlands; tel 3188755 3049; email k.schoemaker@umcutrecht.nl
}

\begin{abstract}
Background: Impairments in executive functions (EF) are consistently associated with attention deficit hyperactivity disorder (ADHD) and to a lesser extent, with disruptive behavior disorder (DBD), that is, oppositional defiant disorder or conduct disorder, in school-aged children. Recently, larger numbers of children with these disorders are diagnosed earlier in development, yet knowledge about impairments in clinically diagnosed preschool children and the role of comorbidity is limited. Therefore, the aim of the current study was to examine EF in clinically referred preschool children with a clinical diagnosis of ADHD, DBD and ADHD + DBD.

Method: Participants were 202 children aged 3.5-5.5 years, 61 with ADHD only, 33 with DBD only, 52 with comorbid ADHD + DBD and 56 typically developing children. Five EF tasks were administered.

Results: Confirmatory factor analysis showed that the two-factor model (inhibition and working memory) fit the data better than a onefactor model in this clinical sample. Preschoolers with ADHD displayed inhibition deficits, also after controlling for IQ. Likewise, preschoolers with DBD displayed impaired inhibition, but when IQ was controlled differences were carried mostly by the effect on the task where motivational demands were high (i.e. when tangible rewards were used). This pattern was also found in the interaction between ADHD and DBD; impaired inhibition in the comorbid group, however, was more severe than in the DBD group. Regarding working memory, few group differences were found.

Conclusions: Clinically diagnosed preschool children with ADHD showed robust inhibition deficits, whereas preschool children with DBD showed impaired inhibition especially where motivational incentives were prominent. Severity of inhibition impairment in the comorbid group was similar to the ADHD group.
\end{abstract}

Keywords: Executive functions, preschool children, DBD, ADHD

\section{Introduction}

School-aged children with behavior problems show robust impairments in executive functions (EF; Oosterlaan, Logan, \& Sergeant, 1998). EF can be defined broadly as the top-down control of cognitive processes to achieve a purpose or goal (Séguin \& Zelazo, 2005). Miyake et al. (2000) proposed that, in adulthood, EF is a unitary construct with three dissociable components: working memory, inhibition and set shifting. Children with attention deficit hyperactivity disorder (ADHD) show EF deficiencies, especially in inhibition (Willcutt et al., 2005). In the meta-analysis by Oosterlaan et al. (1998), however, deficits in inhibition were not uniquely associated with ADHD, but also with the two disruptive behavior disorders (DBD), that is, oppositional defiant disorder (ODD) and conduct disorder (CD). Other studies have shown deficiencies in inhibition in school age children and adolescents with DBD specifically when motivational processes, that is, reward and punishment, are involved (Matthys, van Goozen, de Vries, CohenKettenis, \& Van Engeland,1998; Matthys, van Goozen, Snoek, \& van Engeland, 2004; Schutter, van Bokhoven, Vanderschuren, Lochman, \& Matthys, 2011). Although these studies provided valuable information on the role of EF in school-aged children with ADHD and the DBD, chronic patterns of hyperactivity and behavior problems can already be identified in the preschool years (Shaw, Lacourse, \& Nagin, 2005). Furthermore, there is increasing evidence that diagnoses of ADHD and DBD can be made reliably in preschool children (e.g. Keenan et al., 2007), and an increasing number of children are diagnosed clinically in preschool. It is not clear whether preschoolers with diagnosed, externalizing clinical disorders will show EF deficits similar to those observed in diagnosed school age children or whether such deficits do not emerge until later in development, particularly as characterizing EF in preschoolers is not straightforward. 
Indeed, there is substantial debate regarding the organization of EF in preschool children, that is, whether EF is a unitary construct (Wiebe, Espy, \& Charak, 2008; in a community sample) or if separable components (e.g. working memory, inhibition and shifting) can be identified at this young age (Hughes, Dunn, \& White, 1998; with hard to manage preschoolers). In their review, Garon, Bryson, and Smith (2008) propose that the EF components develop hierarchically during the preschool period (working memory followed by inhibition followed by set shifting), although there is no specific evidence to date to support this developmental timetable.

In recent years there has been increasing interest in the study of EF, especially on inhibition and working memory, in preschool children with behavioral problems. In line with findings with older children, Mariani and Barkley (1997) found impairments on tasks designed to measure inhibition in clinically diagnosed preschoolers with ADHD. Likewise, in community samples, inhibition impairments also have been observed, either when ADHD symptoms are defined categorically (Dalen, Sonuga-Barke, Hall, \& Remington, 2004; Thorell \& Wåhlstedt, 2006; Youngwirth, Harvey, Gates, Hashim, \& Friedman-Weieneth, 2007) or continuously (Berlin \& Bohlin, 2002; Sonuga-Barke, Dalen, Daley, \& Remington, 2002; Tillman, Thorell, Brocki, \& Bohlin, 2008; Von Stauffenberg \& Campbell, 2007). For working memory, results are inconsistent, with some noting an impairment (Mariani \& Barkley, 1997; Thorell \& Wåhlstedt, 2006) and others not (Sonuga-Barke et al., 2002; Youngwirth et al., 2007).

While meta-analyses have confirmed the presence of impaired inhibition task performance in older children with DBD (Morgan \& Lilienfeld, 2000; Oosterlaan et al., 1998), it is unclear whether such deficits also are evident in preschoolers. Results from several studies have revealed inhibitory deficits in preschoolers with DBD symptoms, but these were not robust after controlling for ADHD symptoms (Berlin \& Bohlin, 2002; SonugaBarke et al., 2002; Thorell \& Wåhlstedt, 2006; Youngwirth et al., 2007; but see Raaijmakers et al., 2008 for an exception). By contrast, preschoolers with symptoms of DBD do not appear to show deficits on working memory tasks (Raaijmakers et al., 2008; Thorell \& Wåhlstedt, 2006; Youngwirth et al., 2007).

Attempts to delineate EF impairments in preschoolers with behavior problems at present are incomplete. Because most studies have used community samples with less severely disordered children, further investigation of EF is warranted in clinical samples of preschool children with ADHD and DBD, who have more severe behavior problems. For example, the lack of EF impairment found in preschoolers with DBD might be related to the lower DBD symptom severity in community samples studied thus far.

Furthermore, the role of comorbidity has been largely ignored, despite the fact that about half of the children with ADHD are also diagnosed with ODD, and the percentage of children with ODD who have comorbid
ADHD is even higher (Kutcher et al., 2004). Only one study included a comorbid ADHD + ODD group from a community sample (Youngwirth et al., 2007); these children exhibited deficits on both inhibition and working memory tasks.

The aim of the present study was to examine EF in clinically referred preschool children with a confirmed, clinical diagnosis of ADHD, DBD and ADHD + DBD. A comparison group of typically developing (TD) children was also included. We capitalized on recent advancements in preschool EF assessment including tasks that were designed to preferentially measure inhibition or working memory, were developed specifically for use in this age range, and varied in their motivational demands. Based on results from studies with older diagnosed children, we expected that children with ADHD would show deficits on both inhibitory and working memory tasks, even when controlling for comorbid DBD symptoms. Further, preschoolers with DBD were hypothesized to display selective impairments on inhibitory tasks (but not on those selected to measure working memory), also after controlling for ADHD symptoms, especially when motivational demands were more prominent. Furthermore, we expected that the comorbid group would display inhibition as well as working memory deficits.

\section{Method \\ Participants}

Participants were 202 children aged 3.5-5.5 years with $\operatorname{ADHD}(N=61), \operatorname{DBD}(N=33), \operatorname{ADHD}+\operatorname{DBD}(N=52)$ and TD children $(N=56)$. Children with disorders were referred by general practitioners, well-baby clinics and pediatricians for clinical assessment at the Outpatient Clinic for Preschool Children with Behavioral Problems, Department of Child and Adolescent Psychiatry, University Medical Centre Utrecht. Children were diagnosed as ADHD, DBD (i.e. ODD or CD) or ADHD + DBD on the basis of the strict application of the DSM-IV-TR criteria for these disorders (American Psychiatric Association, 2000). Consensus was reached between a child psychiatrist and a clinical child psychologist using the following data sources: (a) the scores within the clinical range on the Attention Problems scale and the Aggressive Behavior scale of the Child Behavior Checklist completed by parents (CBCL/1.5-5) and the Child Teacher Report Form completed by teachers or day-care caregivers (C-TRF/1.5-5; both: Achenbach \& Rescorla, 2000; Dutch version by Verhulst \& Van der Ende, 2000); (b) the symptoms reported on the Kiddie Disruptive Behavior Schedule (Keenan et al., 2007), a semistructured DSMIV based parent interview for the assessment of ADHD, ODD and CD in preschool children; (c) the scores on the Child Global Assessment Schedule (Schaffer, et al., 1983), a measure of the impairment of the functioning of the child, filled out by the parents as well as the teacher/ caregiver; and (d) the observation of the child's behavior using the Disruptive Behavior Diagnostic Observation Schedule (Wakschlag, Briggs-Gowan, et al., 2008; Wak- 
Table 1. Means (and SD) for the demographics and control variables in the four groups

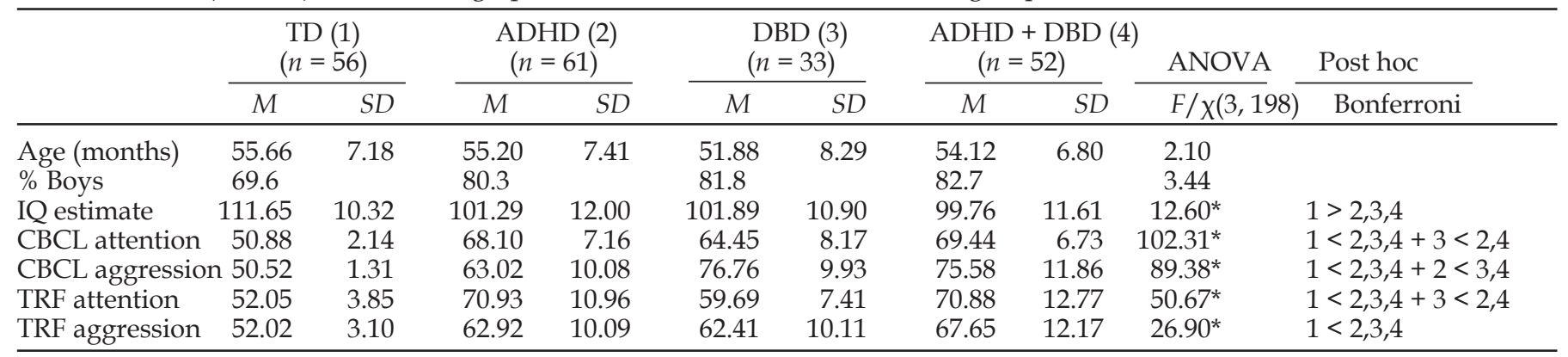

ADHD, attention deficit hyperactivity disorder; CBCL, Child Behavior Checklist; DBD, disruptive behavior disorder; TD, typical developing; TRF, Teacher Report Form. * $p<.001$.

schlag, Hill, et al., 2008), a structured observation that evaluates the child's behavior during tasks systematically varying in the level of challenge and support.

The TD group was recruited from regular primary schools and day-care centers. Children with a score in the normal range on the Attention Problems scale and on the Aggressive Behavior scale of the CBCL and CTRF were included.

All children with an IQ below 70, estimated by the average of the scores on the Raven Colored Progressive Matrices (Raven, Court, \& Raven, 1998) and the Peabody Picture Vocabulary Test-III-NL (Dunn \& Dunn, 2005; Dutch translation by Schlichting, 2005) were excluded. None of the preschoolers in the clinical groups was on medication. The characteristics of the four groups are displayed in Table 1 . The four groups did not differ on age $(p=.102)$ or proportion of males $(p=.329)$. There were group differences in estimated IQ $(p<.001)$, with the TD group significantly outperforming the three clinical groups, who performed similarly to each other.

\section{Procedure}

Children were evaluated in a single, morning session. First, the two measures of intellectual functioning were administered, followed by the EF tasks. All tasks were administered individually by trained master's students in a quiet room with a one-way mirror. One parent was in the room with the child and the assessment was recorded. The tasks were administered in a fixed order and lasted about $2 \mathrm{hr}$, including breaks. After another break the child observation and parent interview were administrated. Parents received nominal financial compensation for participating and children received two small gifts. Written informed consent from the parents was obtained before participating and the study was approved by the Medical Ethical Review Committee of the University Medical Center Utrecht.

\section{Measures}

The EF tasks used in this study were adapted from those used in Wiebe et al. (2011). The computerized tasks are administered through E-Prime version 1.2 (Psychology Software Tools, Pittsburgh, PA). All tasks were preceded by practice trials, to make sure the chil- dren adequately understood, and could perform, the tasks. Three tasks were considered to preferentially measure inhibitory skills, that is, Go-No-Go, Modified Snack Delay, and Shape School - Inhibit Condition, and two more to preferentially assess working memory abilities, that is, Nine Boxes and Delayed Alternation.

The Go-No-Go task is a computerized task where children were instructed to catch as many fish (Go stimuli, $75 \%$ ) as possible by pressing the button when a fish appeared on the screen. They were instructed to let the shark (No-Go stimuli, 25\%) swim by withholding the button press. Auditory feedback was provided when appropriately catching a fish or inappropriately catching a shark. Stimuli were presented for $1,500 \mathrm{~ms}$, with an interstimulus interval of $1,000 \mathrm{~ms}$. The dependent variable was the proportion correct, the number of NoGo trials the child correctly did not press the button divided by the total number of No-Go trials.

Modified Snack Delay is a newly developed task that integrates the motivational context from the original Snack Delay paradigm (Kochanska, Murray, Jacques, Koenig, \& Vandegeest, 1996) with the motor - inhibitory control demands of NEPSY Statue (Korkman, Kirk, \& Kemp, 1998). Children were instructed to stand still like a snowman with their hands on a mat, without talking or moving. In front of the child a glass with a treat underneath and a bell was placed. The child was instructed that when the examiner rang the bell, the child could move again and eat the treat. The task lasted $4 \mathrm{~min}$, during which the examiner progressively distracted the child with various activities (e.g. dropping a pencil, knocking under the table) and culminating in leaving the room for $90 \mathrm{~s}$. During each 5-s interval, four different behaviors categories were rated from DVD by trained raters: moving body, moving hands, talking and 'reward-related behavior' (e.g. eating treat, touching bell). Twenty percent were double coded to determine interrater reliability (mean interrater agreement $=88 \%$ ). The dependent variable was the number of intervals that the child complied with all task rules (not moving, talking or 'reward-related behavior') divided by the total number of intervals (i.e. 48).

The Shape School - Inhibit Condition is a computerized task with cartoon figures with different shapes, colors and expressions, where the naming rule differs in vary- 
Table 2. Correlation between executive function tasks

\begin{tabular}{|c|c|c|c|c|c|}
\hline & Go-No-Go & Modified Snack Delay & Shape School - Inhibit & Delayed Alternation & Nine Boxes \\
\hline Go-No-Go & - & $.25^{* * *}$ & $.36^{* * *}$ & $.21^{* *}$ & $.17^{*}$ \\
\hline Modified Snack Delay & & - & $.34^{* * *}$ & $.23^{* *}$ & $.18^{*}$ \\
\hline Shape School - Inhibit & & & - & $.33^{* * *}$ & $.22 * *$ \\
\hline Nine Boxes & & & & & - \\
\hline
\end{tabular}

$* p<.05 ;{ }^{* *} p<.01 ; * * * p<.001$

ing conditions. In the Inhibit condition, participants had to name the color of the figures with happy faces and suppress the prepotent color naming response when the figure had a sad/frustrated face. The dependent variable was the number of correct responses divided by the total number trials (i.e. $N=18$ ).

In Delayed Alternation, the child had to find a treat underneath one of two identical cups, where after a correct retrieval, the reward alternated to the opposite side in the next trial. There was a 10-s delay between trials, during which the treat was hidden out of the child's sight and the examiner actively distracted the child. A maximum of 16 trials was administrated or if the child made eight consecutive correct responses. The dependent variable was the number of correct retrievals divided by the number of total trials.

In Nine Boxes, children were instructed to find all "Barbapapa" characters hidden in nine different colored boxes (with different shapes on the lid). The child was allowed to open one box per trial, and the boxes were shuffled behind a screen between trials during the 10-s delay. A maximum of 20 trials were administered, until the child found all characters or made five consecutive errors. The dependent variable was the number of correct retrievals divided by modified the total trials.

For the Go-No-Go and Snack Delay tasks, test-retest was good, exceeding .80; the Shape School - Inhibit condition task was adequate (.71) and Delayed Alternation and Nine Boxes were less than desired $(<.70)$ for use with individual children (Espy, Bull, Kaiser, Martin, \& Banet, 2008; Espy, Wiebe, \& Sheffield, 2009). Note that most reliabilities were calculated on somewhat different dependent variables than used here.

\section{Results}

For all analyses, missing data (3.5\%) in the EF measures were imputed, considering age, gender, IQ, groups assignment and performance on other EF tasks as auxiliary variables.

\section{Factor analysis}

Before conducting factor analyses, the correlations between the EF tasks were calculated (Table 2). Confirmatory factor analyses were performed using the AMOS program, where both a one- and two-factor model were tested. In the one-factor model, all tasks loaded on one common factor. In the two-factor model, the Nine Boxes and Delayed Alternation tasks loaded on the work- ing memory factor, and the Shape School, Go-No-Go and Snack Delay loaded on the inhibition factor (see Figure 1). The overall model fit was based on the chisquare test, the root-mean-square error of approximation (RMSEA), comparative fit index (CFI) and Tucker and Lewis Index (TLI). Both models showed adequate fit to the data, one-factor model: $\chi^{2}(5)=6.04, p=.302$; RMSEA $=0.03, \mathrm{TLI}=0.98, \mathrm{CFI}=0.99$; two-factor model: $\chi^{2}(4)=0.47, p=.976$; RMSEA $=0.00, \mathrm{TLI}=1.09, \mathrm{CFI}=$ 1.00. The models were compared with the chi-square difference test. The two-factor model fitted significantly better than the one-factor model $\left(\Delta \chi^{2}=5.57, \Delta d f=1\right.$, $p=.018)$. Subsequently, the two-factor scores were computed using a two-factor exploratory factor analysis in spss (SPSS version 18.0, Chicago, IL, USA), the output was used as dependent variables.

\section{Group differences}

Our aim was to get a detailed picture of the EF performance in preschoolers with ADHD and/or DBD. Therefore, a 2 (ADHD vs. no ADHD) $\times 2$ (DBD vs. no DBD) factorial design (utilizing two dummy variables to represent the factors) was used to compare the EF performance of children with ADHD only (ADHD $=1, \mathrm{DBD}=0)$, with $\mathrm{DBD}$ only $(\mathrm{ADHD}=0, \mathrm{DBD}=1)$, comorbid with both disorders (ADHD $=1, \mathrm{DBD}=1)$ and those with neither ( $\mathrm{TD}$ controls, $\mathrm{ADHD}=0, \mathrm{DBD}=0$ ). This $2 \times 2$ multivariate analysis, instead of an analysis with four independent groups, is the recommended analytic design to test whether the performance of the group with two disorders could be described as an additive combination of the deficits found in the singly disordered groups or was due to an interaction of ADHD and DBD (for a similar procedure, see Willcutt et al., 2001). We studied different levels of dependent variables with this model: first at an overall level, second at a two EF factor level and third at the individual task level, proceeding to the next level only when the preceding was significant.

The $2 \times 2$ groups differed in age (main effect DBD, $p=.023)$, and therefore age was included as a covariate in all analyses. There is a debate regarding whether or not IQ should be included as a covariate in the analyses. On the one hand, including IQ as a covariate ensures that deficits in clinical groups cannot be explained by known group differences in intelligence. On the other hand, both ADHD and DBD typically are associated with mild IQ differences in comparison to individuals without these disorders. Controlling for IQ then 
Table 3. Unadjusted means (and SD) of the executive function factors and tasks in the four groups

\begin{tabular}{|c|c|c|c|c|c|c|c|c|c|c|c|}
\hline & \multicolumn{2}{|c|}{$\begin{array}{c}\mathrm{TD} \\
(\mathrm{N}=56)\end{array}$} & \multicolumn{2}{|c|}{$\begin{array}{l}\text { ADHD only } \\
(\mathrm{N}=61)\end{array}$} & \multicolumn{2}{|c|}{$\begin{array}{l}\text { DBD only } \\
(\mathrm{N}=33)\end{array}$} & \multicolumn{2}{|c|}{$\begin{array}{l}\text { ADHD+DBD } \\
(\mathrm{N}=52)\end{array}$} & \multirow{2}{*}{$\begin{array}{l}\text { Main effect } \\
\text { ADHD }^{\mathrm{a}} \\
\mathrm{F}(1,197)\end{array}$} & \multirow{2}{*}{$\begin{array}{c}\begin{array}{c}\text { Main effect } \\
\text { DBD }^{\mathrm{a}}\end{array} \\
\mathrm{F}(1,197)\end{array}$} & \multirow{2}{*}{$\begin{array}{c}\begin{array}{c}\text { Interaction } \\
\mathrm{ADHD}^{2} \times \mathrm{DBD}^{\mathrm{a}}\end{array} \\
\mathrm{F}(1,197)\end{array}$} \\
\hline & $\mathrm{M}$ & $\overline{\mathrm{SD}}$ & $\mathrm{M}$ & $\mathrm{SD}$ & $\mathrm{M}$ & $\overline{\mathrm{SD}}$ & $\overline{\mathrm{M}}$ & $\mathrm{SD}$ & & & \\
\hline Inhibition factor & 0.72 & 0.84 & -0.31 & 0.92 & -0.14 & 0.92 & -0.35 & 0.93 & $29.11^{* * *}$ & $7.54^{* *}$ & $8.18^{* *}$ \\
\hline Modified Snack Delay & 0.34 & 0.24 & 0.13 & 0.17 & 0.17 & 0.21 & 0.11 & 0.17 & $28.42^{* * *}$ & $7.12^{* *}$ & $5.74^{*}$ \\
\hline Shape School - Inhibit & 0.90 & 0.19 & 0.71 & 0.28 & 0.71 & 0.27 & 0.69 & 0.27 & $13.62^{* * *}$ & $4.08^{*}$ & 3.20 \\
\hline Working memory factor & 0.24 & 0.97 & -0.03 & 1.01 & -0.10 & 1.04 & -0.17 & 0.99 & 2.82 & 0.52 & 0.03 \\
\hline
\end{tabular}

All variables of the EF tasks are proportionally correct and factors are Z-scores. ADHD, attention deficit hyperactivity disorder; DBD, disruptive behavior disorder; TD, typically developing.

a. The results of analyses with age as covariate.

${ }^{*} p<.05 ;{ }^{* *} p<.01 ; * * * \quad<.001$

may remove inappropriately the overlapping portion of the variance that is associated with the disorder. Because of these contrasting views, all results are reported both with and without controlling for IQ (see, e.g. also Willcutt et al., 2001). In the present study, IQ accounted for $14 \%$ of the variance in the inhibition factor and $4 \%$ of the variance in the working memory factor.

First level: overall EF. First, to test whether either ADHD or DBD was associated with deficits at the overall EF level, repeated measure multivariate analyses of covariance (MANCOVAs) were conducted with the two dummy-coded diagnostic indicators as the between subjects variables and the inhibition and working memory factor as the within-subject variable. Results of the repeated measure MANCOVAs show that there was a significant main effect (controlling for age, but not IQ) of $\operatorname{ADHD}(F=33.56, p=.000), \operatorname{DBD}(F=8.04, p=.005)$ and the respective interaction $(F=6.02, p=.015)$, indicating that children with ADHD, DBD and ADHD + DBD diagnoses performed more poorly at the overall EF level (collapsed across the two EF factors). Adding IQ to the model as a covariate resulted in the same pattern of results, $\operatorname{ADHD}(F=23.04, p=.000), \operatorname{DBD}(F=4.59$, $p=.033) \mathrm{ADHD} \times \mathrm{DBD}(F=3.79, p=.053)$. Therefore, further testing of the impact of diagnostic category on each EF factor was warranted.

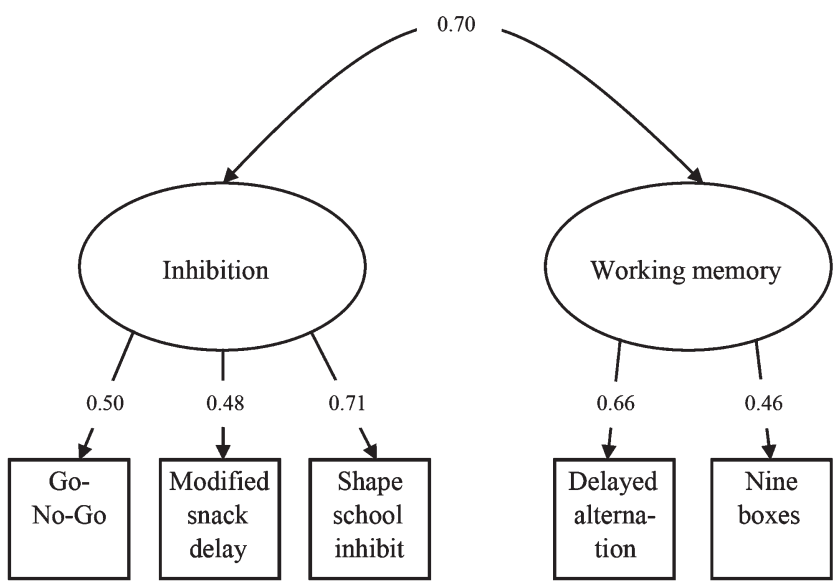

Figure 1. Two-factor model with standardized regression weights (and correlation between factors)
Second level: EF factors. Second, to test whether either ADHD or DBD was associated with deficits on the EF measures independent of the other disorder, separate $2 \times 2($ ADHD $\times$ DBD) MANCOVA were conducted for the EF factors, followed by planned contrasts. Table 3 presents the unadjusted means of the four groups on the individual EF tasks and two-factor scores, together with the results of the $2 \times 2$ MANCOVAs controlling for age only. The analyses revealed a significant main effect of ADHD, a main effect for DBD and an interaction effect between ADHD and DBD for the inhibition factor, but not for the working memory factor. We added IQ to the model as an additional covariate besides age (see Figure 2). For the inhibition construct the main effect of $\operatorname{ADHD}(F=20.50, p=.001)$, of DBD $(F=4.65, p=.032)$ and of $\mathrm{ADHD} \times \mathrm{DBD}(F=5.90, p=.016)$ remained significant. For the working memory construct, the ADHD, $\mathrm{DBD}$ and $\mathrm{ADHD} \times \mathrm{DBD}$ effects remained nonsignificant with IQ controlled.

Following planned contrasts were conducted, for the significant effects, in which the performance of each clinical group was directly compared with the performance of the TD group. Each clinical group differed significantly from the TD group $(p<.05)$ on the inhibition factor with and without controlling for IQ.

Third level: EF tasks. The results at the level of the inhibition factor was significant, so follow-up MANCOVA analyses were conducted for the three inhibition tasks, to determine which tasks contributed to the observed group differences on the construct. There was an ADHD main effect and a DBD main effect evident on each of the three inhibition tasks. For the ADHD $\times$ DBD effect, the inhibition differences were carried mostly by a significant interaction effect on Modified Snack Delay (Table 3). Adding IQ to the model altered the pattern of results somewhat for the DBD main effect, now the inhibition differences were carried mostly by a significant effect on the Modified Snack Delay task $(F=5.34$, $p=.022)$ and not by the Go-No-Go and Shape School task anymore. The ADHD main effect remained significant for all three inhibition tasks and the ADHD $\times$ DBD effect remained significant for the Modified Snack Delay task only $(F=4.57, p=.034)$. 


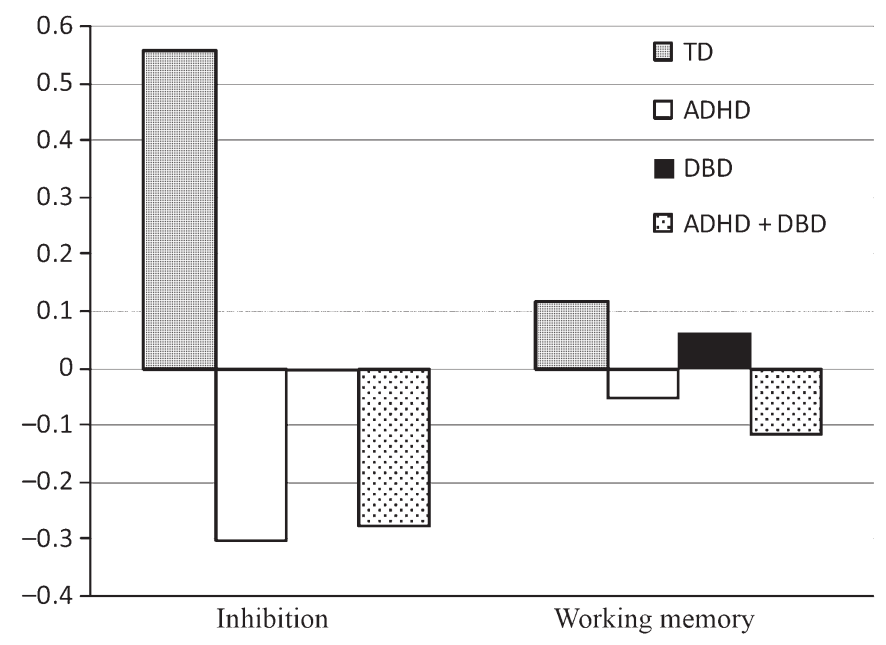

Figure 2. Marginal means of the executive function factors adjusted for age and IQ

For the inhibition tasks planned contrasts were specified in which the performance of each clinical group was directly compared with the performance of the TD group. Each clinical group differed significantly from the TD group $(p<.05)$ on the inhibition tasks. Adding IQ to the model the results remained the same, with one exception, the contrast between DBD and TD on Shape School - Inhibit Condition was marginally significant $(p=.058)$.

Controlling comorbid symptoms. Finally, we used this model and added dimensional measures of behavior problems as a covariate. Thus, to test whether there were still significant main effects of ADHD and/or DBD when controlling for comorbid symptoms, additional $2 \times 2$ MANCOVAs were conducted with the dimensional measures of the other disorder as a covariate (Aggressive Behavior and Attention Problems scores on CBCL/TRF), along with age and IQ.

First, the specificity of the association between ADHD and inhibition impairments was examined by adding CBCL aggression scores as a covariate. After controlling for age, IQ and CBCL aggression scores, the ADHD main effect remained significant for the inhibition factor, $F(1,197)=19.53, p<.001$. This warranted us to conduct the analyses for each individual task, the effects remained significant as well: Go-No-Go, $F(1,197)=4.44$, $p=.036$; Modified Snack Delay, $F(1,197)=19.95, p<.001$; and Shape School - Inhibit, $F(1,197)=9.21, p=.003$. Second, to test the specificity of the association between DBD and inhibition impairments was tested by adding CBCL attention scores as a covariate. When age, IQ and CBCL attention scores were included as covariates, the previously significant main effect was no longer significant for the inhibition factor. Similar pattern of results were found when TRF (instead of CBCL) aggression and attention problems scores were used as a covariate.

\section{Discussion}

The aim of the current study was to investigate EF in preschool children with ADHD and DBD taking into account comorbidity. A clinically referred sample of preschoolers with ADHD, DBD and both disorders was included as well as a TD group. When the structure of EF was examined in the present sample of clinically diagnosed preschoolers, a two-factor model (inhibition and working memory) fit the data better than a one-factor model. This pattern of findings is in contrast to those of Wiebe et al. $(2008,2011)$ who found a one-factor model in a large sample of TD children without frank psychopathology. The two-factor structure probably fit better in the clinically diagnosed children reflecting the underlying pattern of clinical impairments.

Regarding inhibition, results of the present study showed, first, that preschool children with ADHD (independent of DBD) consistently showed substantial and specific inhibition deficits (i.e. on the inhibition factor and on all three inhibition tasks), also after controlling IQ and dimensionally for DBD symptoms. These results are in line with studies in community samples (e.g. Berlin \& Bohlin, 2002; Youngwirth et al., 2007) and the only study in a clinical sample (Mariani \& Barkley, 1997). The latter study, however, did not account for DBD symptoms. The present study is the first one to show specific inhibition deficits in a clinical sample of preschoolers with ADHD irrespective of DBD comorbidity, either examined from a categorical or a dimensional point of view.

Second, results of the present study showed an impairment on the inhibition factor in preschool children related to DBD diagnosis that was robust after controlling for IQ, and this DBD-related impairment was most evident on the Modified Snack Delay task. In comparison to TD children, DBD-only children performed more poorly on all inhibition tasks, in line with results from studies of older children (see meta-analyses: Morgan \& Lilienfeld, 2000; Oosterlaan et al., 1998). The Modified Snack Delay task, that is, the inhibition task in which salient motivational factors (i.e. food reward) are included in addition to the motor inhibitory demands was particularly sensitive to differences to DBD in this preschool age range. This finding may be consistent with results from studies in older children and adolescents using tasks in which reward and punishment are included (Fairchild et al., 2009; Matthys et al., 2004; Schutter et al., 2011), although the nature of these tasks differ substantially and the comparability of these tasks across age ranges is unknown. Because the DBD-related differences on the inhibition factor disappeared after controlling for ADHD symptoms (attention problems), it seemed that performance on inhibition tasks was associated with ADHD symptoms and not with the DBD diagnosis itself. Given the high prevalence of subclinical levels of ADHD symptoms that co-occur with frank DBD disorder, particularly in 
this age range, impaired inhibition can be considered a characteristic of children with DBD, although the 'true' source of inhibition deficits might not the DBD per se.

Third, the comorbid (ADHD + DBD) group displayed inhibition deficits, also after controlling for IQ. The pattern of the inhibition impairment was similar to the pattern of the DBD group, that is, differences remained only on the Modified Snack Delay task when IQ was controlled. Impaired inhibition in the comorbid group, however, was more severe than in DBD group. In conclusion, in terms of severity of impairment the comorbid group was similar to the ADHD group, whereas in terms of pattern of the inhibition impairment the comorbid group was similar to the DBD group.

Regarding working memory, no differences among the groups were found on the working memory factor, which is consistent with the findings of other studies (e.g. Sonuga-Barke et al., 2002). Because these tasks, or similar variants, have been shown to be sensitive to process differences in preschoolers with other disorders, such as prematurity (Espy et al., 2004), it does not appear to be a task measurement issue per se, although reliability of these tasks was lower than the inhibition tasks, which limits the true variance that can be attributed to variables of interest. The reasons for not finding a working memory deficit might be twofold, with different reasons for the DBD and ADHD group. Moffitt (1993) reviewed neuropsychological studies of children with CD and found that these children showed substantive verbal impairments; these impairments were more severe than performance impairments. So it might be that children with DBD especially show verbal working memory problems. Unfortunately, in the present study, the tasks were designed to enable performance of very young children, so the demands were not modality specific, but certainly were designed to assess spatial working memory to a greater degree. Second, a meta-analysis (Willcutt et al., 2005) showed that school age children and adolescents with ADHD displayed working memory impairments. So it could be that working memory impairments become more apparent at later ages for children with ADHD.

Some limitations should be considered when interpreting the results. Concerning the assessment of EF, the difficulty of some tasks and the age of the sample restricted the broad assessment which we aimed. As a result, set shifting was unable to be assessed. The development of tasks appropriate to assess EF in preschool children, especially in the younger ones, remains a challenge. Another limitation is a relatively small sample that prevented us to examine specific developmental differences, which could have provided a more thorough characterization of impairments across the preschool period.

Despite these limitations, this study is the first on EF in clinically diagnosed preschool children with ADHD, DBD and both disorders comorbidly. Results show inhibition impairments in all three groups already at this young age, which is most pronounced in the ADHD group. Future research should assess EF in children with ADHD and/or DBD longitudinally to gain insight in the development of EF over time in these disorders and the role of EF impairments as factors involved in the persistence of ADHD and/or DBD. Likewise, the effect of EF impairment on various domains of functioning, such as academic outcome and peer relations, needs to be examined. Thus, a better understanding of the role of EF in the psychopathology of ADHD and DBD ultimately may improve intervention strategies for these disorders.

\section{Key points}

- Clinically diagnosed preschool children with ADHD show inhibition deficits.

- Clinically diagnosed preschool children with DBD show impaired inhibition especially when motivational factors are involved.

- Preschool children with ADHD and/or DBD display no working memory deficits.

Acknowledgments - We are grateful to the parents and children who participated in this study. We also thank Sarah Laschen, Eva van der Kleij and Justa Kamstra for their assistance with the data collection.

\section{References}

Achenbach, T.M., \& Rescorla, L.A. (2000). Manual for the ASEBA preschool forms and profiles. Burlington: Research Center for Children, Youth \& Families, University of Vermont.

American Psychiatric Association (2000). Diagnostic and statistical manual of mental disorders (TR) (4th edn). Washington, DC: APA.

Berlin, L., \& Bohlin, G. (2002). Response inhibition, hyperactivity, and conduct problems among preschool children. Journal of Clinical Child Psychology, 31, 242-251.

Dalen, L., Sonuga-Barke, E.J.S., Hall, M., \& Remington, B. (2004). Inhibitory deficits, delay aversion and preschool $\mathrm{AD} / \mathrm{HD}$; implications for the dual pathway model. Neural Plasticity, 11, 1-11.

Dunn, L.M., \& Dunn, L.M. (2005). Peabody picture vocabulary test (III-NL) [Dutch version by L. Schlichting]. Amsterdam: Hartcourt Assessment.

Espy, K.A., Bull, R., Kaiser, H., Martin, J., \& Banet, M. (2008). Methodological and conceptual issues in understanding the development of executive control in the preschool period. In V. Anderson, R. Jacobs, \& P.J. Anderson (Eds.), Executive functions and the frontal lobes: A lifespan perspective (pp. 105-121). New York: Taylor \& Francis. 
Espy, K.A., McDiarmid, M.D., Cwik, M.F., Senn, T.E., Hamby, A., \& Stalets, M.M. (2004). The contributions of executive functions to emergent mathematic skills in preschool children. Developmental Neuropsychology, 26, 465-486.

Espy, K.A., Wiebe, S.A., \& Sheffield, T. (2009, February). Test- retest reliability for new tasks to assess executive control in preschoolers. Poster presented at conference of the International Neuropsychology Society (INS), Atlanta, GA.

Fairchild, G., Van Goozen, S.H.M., Stollery, S.J., Aitken, M.R.F., Savage, J., Moore, S.C., \& Goodyer, I.M. (2009). Decision making and executive function in male adolescents with early-onset or adolescence-onset conduct disorder and control subjects. Biological Psychiatry, 66, 162-168.

Garon, N., Bryson, S.E., \& Smith, I.M. (2008). Executive function in preschoolers: A review using an integrative framework. Psychological Review, 134, 31-60.

Hughes, C., Dunn, J., \& White, A. (1998). Trick or treat? Uneven understanding of mind and emotion and executive dysfunction in hard-to-manage preschoolers. Journal of Child Psychology and Psychiatry, 39, 981-994.

Keenan, K., Wakschlag, L.S., Danis, B., Hill, C., Humphries, M., Duax, J., \& Donald, R. (2007). Further evidence of the reliability and validity of DSM-IV ODD and CD in preschool children. Journal of American Academy of Child and Adolescent Psychiatry, 26, 457-468.

Kochanska, G., Murray, K., Jacques, T.Y., Koenig, A.L., \& Vandegeest, K.A. (1996). Inhibitory control in young children and its role in emerging internalization. Child Development, 67, 490-507.

Korkman, M., Kirk, U., \& Kemp, S. (1998). NEPSY: A developmental neuropsychological assessment. Boston: The Psychological Association.

Kutcher, S., Aman, M., Brooks, S.J., Buitelaar, J., Van Daalen, E., Fegert, J., . . ., Tyona, S. (2004). International consensus statement on attention-deficit/hyperactivity disorder (ADHD) and disruptive behaviour disorders (DBDs): Clinical implications and treatment practice suggestions. European Neuropsychopharmacology, 14, 11-28.

Mariani, M.A., \& Barkley, R.A. (1997). Neuropsychological and academic functioning in preschool boys with attention deficit hyperactivity disorder. Developmental Neuropsychology, 13, 111-129.

Matthys, W., van Goozen, S.H.M., de Vries, H., CohenKettenis, P.T., \& van Engeland, H. (1998). The dominance of behavioural activation over behavioural inhibition in conduct disordered boys with or without attention deficit hyperactivity disorder. Journal of Child Psychology and Psychiatry, 39, 643-651.

Matthys, W., Van Goozen, S.H.M., Snoek, H., \& van Engeland, H. (2004). Response perseveration and sensitivity to reward and punishment in boys with oppositional defiant disorder. European Child and Adolescent Psychiatry, 13, 362-364.
Miyake, A., Friedman, N.P., Emerson, M.J., Witzki, A.H., Howerter, A., \& Wager, T.D. (2000). The unity and diversity of executive functions and their contributions to complex frontal lobe tasks: A latent variable analysis. Cognitive Psychology, 41, 49-100.

Moffitt, T.E. (1993). The neuropsychology of conduct disorder. Development and Psychopathology, 5, 135-151.

Morgan, A.B., \& Lilienfeld, S.O. (2000). A meta-analytic review of the relation between antisocial behavior and neuropsychological measures of executive function. Clinical Psychology Review, 20, 113-136.

Oosterlaan, J., Logan, G.D., \& Sergeant, J.A. (1998). Response inhibition in $\mathrm{AD} / \mathrm{HD}, \mathrm{CD}$, comorbid $\mathrm{AD} /$ $\mathrm{HD}+\mathrm{CD}$, anxious, and control children: A meta-analysis of studies with the stop task. Journal of Child Psychology and Psychiatry, 39, 411-425.

Raaijmakers, M.A.J., Smidts, D.P., Sergeant, J.A., Maassen, G.H., Posthumus, J.A., Van Engeland, H., \& Matthys, W. (2008). Executive functions in preschool children with aggressive behavior: Impairments in inhibitory control. Journal of Abnormal Child Psychology, 36, 1097-1107.

Raven, J.C., Court, J.H., \& Raven, J. (1998). Raven coloured progressive matrices. Oxford: Oxford Psychologist Press.

Schaffer, D., Goud, M.S., Brasic, J., Ambrosini, P., Fisher, P., Bird, H., \& Aluwhalia, S. (1983). A children's global assessment scale (C-GAS). Archives of General Psychiatry, 40, 1228-1231.

Schlichting, L. (2005). Peabody picture vocabulary test III-NL. Amsterdam: Hartcourt Assessment. Schutter, D.J.L.G., van Bokhoven, I., Vanderschuren, L.J.M.J., Lochman, J.E., \& Matthys, W. (2011). Risky decision making in substance dependent adolescents with a disruptive behavior disorder. Journal of Abnormal Child Psychology, 39, 333-339.

Séguin, J.R., \& Zelazo, P.D. (2005). Executive function in early physical aggression. In R.E. Tremblay, W.W. Hartup, \& J. Archer (Eds.) Developmental origins of aggression (pp. 307-329). New York: Guilford.

Shaw, D.S., Lacourse, E., \& Nagin, D.S. (2005). Developemntal trajectories of conduct problems and hyperactivity from ages 2 to 10. Journal of Child Psychology and Psychiatry, 46, 931-942.

Sonuga-Barke, E.J.S., Dalen, L., Daley, D., \& Remington, B. (2002). Are planning, working memory, and inhibition associated with individual differences in preschool ADHD symptoms? Developmental Neuropsychology, 21, 255-272.

Thorell, L.B., \& Wa ${ }^{\circ}$ hlstedt, C. (2006). Executive functioning defcits in relation to symptoms of ADHD and/or ODD in preschool children. Infant and Child Development, 15, 503- 518.

Tillman, C.M., Thorell, L.B., Brocki, K.C., \& Bohlin, G. (2008). Motor response inhibition and execution in the stop-signal task: Development and relation to ADHD behaviors. Child Neuropsychology, 14, 42-59. 
Von Stauffenberg, C., \& Campbell, S.B. (2007). Predicting the early developmental course of symptoms of attention deficit hyperactivity disorder. Journal of Applied Developmental Psychology, 28, 536-552.

Wakschlag, L.S., Briggs-Gowan, M.J., Hill, C., Danis, B., Leventhal, L., Keenan, K., . . ., Carter, A.S. (2008). Observational assessment of preschool disruptive behavior, Part II: Validity of the disruptive behavior diagnostic observation schedule (DB-DOS). Journal of American Academy of Child and Adolescent Psychiatry, 47, 632-640.

Wakschlag, L.S., Hill, C., Carter, A.S., Danis, B., Egger, H.L., Keenen, K., . . ., Briggs-Gowan, M.J. (2008). Observational assessment of preschool disruptive behavior, Part I: Reliability of the disruptive behavior diagnostic observation schedule (DB-DOS). Journal of American Academy of Child and Adolescent Psychiatry, 47, 622-631.

Wakschlag, L.S., \& Keenan, K. (2001). Clinical significance and correlates of disruptive behavior in environmentally at-risk preschoolers. Journal of Clinical Child Psychology, 30, 262- 275.

Wiebe, S.A., Espy, K.A., \& Charak, D. (2008). Using confirmatory factor analysis to understand executive control in preschool children: I. Latent structure. Developmental Psychology, 44, 575-587.
Wiebe, S.A., Sheffield, T., Nelson, J.M., Clark, C.A.C., Chevalier, N., \& Espy, K.A. (2011). The structure of executive function in 3-year-olds. Journal of Experimental Child Psychology, 108, 436-452.

Willcutt, E.G., Doyle, A.E., Nigg, J.T., Stephen, V., Faraone, S.V., \& Pennington, B.F. (2005). Validity of the executive function theory of attention-deficit/hyperactivity disorder: A meta-analytic review. Biological Psychiatry, 57, 1336-1346.

Willcutt, E.G., Pennington, B.F., Boada, R., Ogline, J.S., Tunick, R.A., Chhabildas, N.A., \& Olson, R.K. (2001). A comparison of the cognitive deficits in reading disability and attention-deficit/hyperactivity disorder. Journal of Abnormal Psychology, 110, 15-172.

Youngwirth, S.D., Harvey, A.H., Gates, E.C., Hashim, R.L., \& Friedman-Weieneth, J.L. (2007). Neuropsychological abilities of preschool-aged children who display hyperactivity and/or oppositional-defiant behavior problems. Child Neuropsychology, 13, 422-443. 